\title{
CEGUERA NOCTURNA Y XEROFTALMÍA TRAS CIRUGÍA DE OBESIDAD MÓRBIDA
}

\section{NIGHT BLINDNESS AND XEROPHTHALMIA AFTER SURGERY FOR MORBID OBESITY}

\author{
LÓPEZ-RODRÍGUEZ $\mathrm{N}^{1}$, FAUS $\mathrm{F}^{1}$, SIERRA J ${ }^{1}$, BALLARÍN T ${ }^{1}$, PUEYO $\mathrm{M}^{2}$, ALBALAD E ${ }^{2}$
}

\section{RESUMEN}

Caso clínico: Se describen los hallazgos oculares debidos a un déficit de vitamina A en un varón de 50 años. Fue sometido a una cirugía de bypass intestinal dos años antes. Después de tratamiento con vitamina A oral, los síntomas mejoraron.

Discusión: La incidencia de obesidad mórbida sigue aumentando alarmantemente en todo el mundo, siendo actualmente el tratamiento mas adoptado en la mayoría de los pacientes la cirugía de bypass intestinal. Este tipo de cirugía puede provocar un déficit de vitamina A, con importantes consecuencias oftalmológicas, que podrían incluso llegar a la ceguera sin un correcto tratamiento. Por consiguiente, se debería considerar seriamente esta patología hasta ahora poco frecuente en países desarrollados.

Palabras clave: Deficiencia de A, xeroftalmía, ceguera nocturna, obesidad mórbida, cirugía bariátrica.

\begin{abstract}
Case report: We describe ocular findings due to a vitamin A deficiency in a 50-year-old man. The patient had undergone intestinal bypass surgery two years before. After therapy with oral vitamin A the symptoms improved.

Discussion: The incidence of morbid obesity is increasing throughout much of the developed world, with intestinal bypass surgery the treatment of choice for most people with the condition. This type of surgery can lead to a vitamin A deficiency, with remarkable ophthalmological consequences, which without correct treatment may ultimately cause blindness. For this reason, the pathology, even though rare at present, must considered seriously (Arch Soc Esp Oftalmol 2007; 82: 133136).
\end{abstract}

Key words: Vitamin A deficiency, xerophthalmia, night blindness, morbid obesity, bariatric surgery.

Recibido: 20/6/06. Aceptado: 30/10/07.

Servicio de Oftalmología. Hospital Royo Villanova. Zaragoza. España.

1 Licenciado en Medicina.

2 Doctor en Medicina.

Correspondencia:

Nuria López Rodríguez

Hospital Royo Villanova

Avda. San Gregorio, 30

50015 Zaragoza

España

E-mail: nurialpz@eresmas.com 


\section{INTRODUCCIÓN}

La vitamina A es una vitamina liposoluble que a nivel ocular ayuda al mantenimiento de membranas mucosas y desempeña un papel muy importante en la adaptación de la retina a la luz. Existen diferentes causas para un déficit vitamínico, entre ellas la malabsorción debida a un bypass intestinal como es el caso del paciente que se describe.

\section{CASO CLÍNICO}

Varón de 50 años al que se le realizó en enero de 2004 una derivación biliopancreática de Scopinaro por obesidad mórbida. El paciente presenta una esteatosis hepática y un síndrome malabsortivo. Está en tratamiento con vitamina B12 por anemia crónica y con vitamina $\mathrm{K}$ por una actividad de protrombina disminuida.

En enero de 2006 se le realiza una pieloinfundibulonefrolitotomía con fístula urinaria postoperatoria.

En abril de 2006 el paciente es remitido al servicio de oftalmología por ceguera nocturna de progresión en 3 meses. El paciente además refería sensación de cuerpo extraño y ojo rojo. A la exploración la agudeza visual era de la unidad en ambos ojos. El examen con lámpara de hendidura mostraba un BUT muy disminuido (fig. 1), xerosis conjuntival y manchas de Bitot (fig. 2) en ambos ojos. También se podía observar observar un fino punteado epitelial conjuntivo corneal en la tinción con fluoresceína. En el test de Schirmer I bajo anestesia

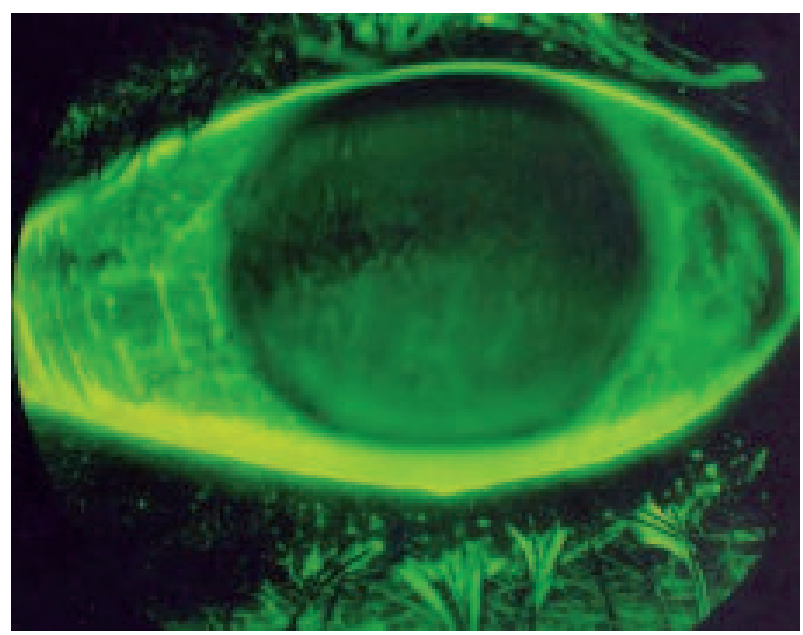

Fig. 1: Disminución del BUT.

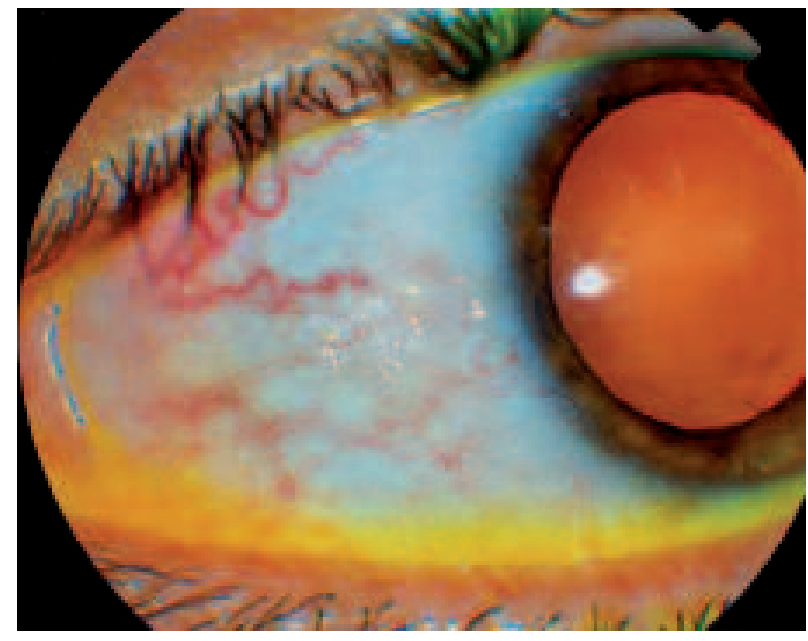

Fig. 2: Xerosis conjuntival y mancha de Bitot.

se observaron valores mayores de $15 \mathrm{~mm}$. Oftalmoscópicamente se apreció un moteado blanquecino en media periferia sin afectación macular (fig. 3). El nivel plasmático de retinol era de $0,07 \mathrm{mg} / \mathrm{l}$ (nivel normal 0,30-0,8 mg/l).

Ante la gravedad potencial del cuadro se comienzó un tratamiento oral con vitamina A y enzimas pancreáticos para favorecer su absorción a la espera de recibir tratamiento intramuscular, sin lograr apenas mejoría.

Concomitantemente, debido a la nefrolitiasis complicada (absceso intrarrenal), al paciente se le realiza una nefrectomía con sangrado intenso, que

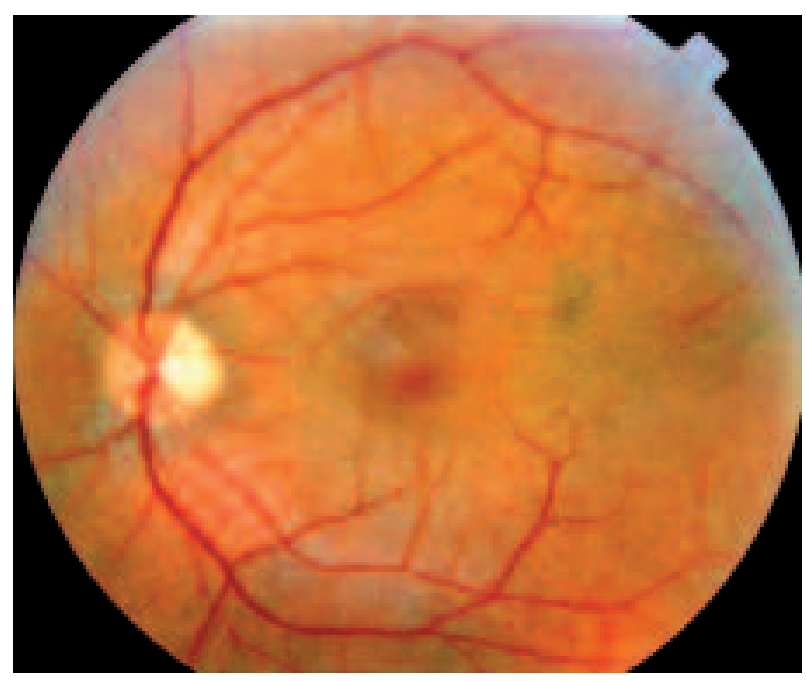

Fig. 3: Moteado blanquecino en media periferia, sin afectación macular. 
requiere cinco concentrados de hematíes. Tras dicho proceso el paciente refiere una ligera mejoría de su sintomatología, a pesar de haber suprimido tratamiento oral por el ayuno postquirúrgico.

Finalmente se le administraron 300.000 UI de vitamina A intramuscular consiguiendo una mejoría inmediata de los síntomas subjetivos, aunque las manifestaciones oftalmoscópicas tardaron tres meses en desaparecer.

\section{DISCUSIÓN}

El bajo consumo de vitamina A por un período prolongado es la causa más común de hipovitaminosis A. Sin embargo, la carencia puede estar influenciada por otros factores como malabsorción de grasas por enfermedades pancreáticas o cirugías de bypass intestinal, o por defectos en el transporte o almacenaje de la misma como en patologías hepáticas.

En el caso de este paciente existe un hígado graso que limita el almacenamiento y un síndrome malabsortivo con esteatorrea por el bypass intestinal, lo que justifica los niveles tan bajos de retinol sérico.

La primera manifestación de la hipovitaminosis A suele ser la ceguera nocturna, que aparece sobre los 2 años tras la deprivación, aunque con el uso del adapto-electrorretinograma a la oscuridad puede ser detectada mucho antes (sobre medio año tras la deprivación) (1).

El caso que se presenta es un cuadro más severo con importante xeroftalmía y afectación de fondo de ojo. En casos previos descritos $(2,3)$, pacientes con niveles similares de retinol únicamente han presentado ceguera nocturna, por lo que suponemos que, en la severidad del cuadro, han podido intervenir otros factores. Quizás la nefrolitotomía y el posterior cuadro infeccioso hayan generado un estrés metabólico que disminuya la síntesis proteica y aumente el catabolismo de proteínas como la proteína ligada al retinol (encargada del transporte de la vitamina A hacia los tejidos diana) lo cual agrave el cuadro de hipovitaminosis (4).

Estamos asistiendo a un aumento progresivo de casos de obesidad en los países desarrollados, y debido al fracaso de los múltiples regímenes dietéticos, cada vez se recurre más a la cirugía para reducir el sobrepeso. Existen dos tipos de cirugía, restrictiva (actúa sobre estómago) y malabsortiva (bypass intestinal). Esta última técnica es más efectiva pero también conlleva más riesgo de pérdida de proteínas, minerales y vitaminas liposolubles, entre ellas la vitamina A.

Una patología como la xeroftalmía, poco frecuente en países desarrollados, puede aumentar exponencialmente, y puesto que las complicaciones pueden ser potencialmente graves e irreversible, deberíamos estar más alerta. Los pacientes operados deben ser controlados conjuntamente por cirujanos y oftalmólogos tras los primeros meses de la cirugía, para detectar tempranamente los déficits vitamínicos y valorar la posibilidad de suplementos antes de la aparición de los síntomas. Así mismo, previo a la cirugía, se debería facilitar una detallada información al paciente tanto de los posibles riesgos oculares como del muy probable tratamiento posterior necesario para prevenirlos (5).

\section{BIBLIOGRAFÍA}

1. Wachtmeister L, Bjorkhem I, Diczfalusy U, Emami A. Attempts to define the minimal serum level of vitamin $A$ required for normal visual function in a patient with severe fat malabsortion. Acta Ophthalmol (Copenh) 1988; 66: 341-348.

2. Pitchon E, Sahli O, Borruat FX. Night blindness, yellow vision, and yellow skin: symptoms and sings of malabsorption. Klin Monatsbl Augenheilkd 2006; 223: 443-446.

3. Apushkin MA, Fishman GA. Improvement in visual function and fundus findings for a patient with vitamin A-deficient retinopathy. Retina 2005; 25: 650-652.

4. Yarborough GW, Wilson FA, Feman S, Charles S, Chytil $F$, O'Leary JP. Retinopathy following jejunoileal bypass surgery: report of a case. Int J Obes 1982; 6: 253-258.

5. Lee WB, Hamilton SM, Harris JP, Schwab IR. Ocular complications of hypovitaminosis a after bariatric surgery. Ophthalmology 2005; 112: 1031-1034. 